(C) 2021 IEEE. Personal use of this material is permitted. Permission from IEEE must be obtained for all other uses, in any current or future media, including reprinting/republishing this material for advertising or promotional purposes, creating new collective works, for resale or redistribution to servers or lists, or reuse of any copyrighted component of this work in other works.

Please cite as:

Tabuenca, B., Börner, D., \& Kalz, M. (2021). Effects of an ambient learning display on noise levels and perceived learning in a secondary school. IEEE Transactions on Learning Technologies. doi: 10.1109/TLT.2021.3056038.

\title{
Effects of an Ambient Learning Display on Noise Levels and Perceived Learning in a Secondary School
}

\author{
Bernardo Tabuenca, Senior Member, IEEE, Dirk Börner, and Marco Kalz
}

\begin{abstract}
Recent reviews addressing the impact of noise exposure in teaching and learning situations conclude negative effects on learning performance. Providing objective real-time feedback on noise is key for teachers and students to adjust it into suitable levels. This experimental work presents the results from a study exploring the visual feedback based on noise level and the impact on students' $(n=198)$ perceived learning performance collected in 24 sessions. The results suggest persuasive effects of the ambient display on the groups and an improvement of noise awareness in students. Measurements of perceived learningperformance, and perceived noise were collected and correlated with the objective noise samples concluding poorer perceived learning performance in noisiest groups. Finally, implications for further research as well as lessons learned to moderate noise levels in classrooms using ambient displays are discussed.
\end{abstract}

Index Terms-Ambient displays, feedback amplifiers, internet of things, mobile agents, learning analytics, noise, smart learning environments.

\section{INTRODUCTION}

$\mathrm{T}$ HE debate on noise in classrooms and its consequences is a recurring theme in educational institutions leading to the creation of associations and campaigns to promote good practices to handle noise [1]-[6]. Different studies corroborate the unfavorable impact of noise on academic performance [7][14]. Nonetheless, the higher or lower voice levels do not only condition the noise level in the classroom.

There are several internal and external factors involved: the

This paragraph of the first footnote will contain the date on which you submitted your paper for review. It will also contain support information, including sponsor and financial support acknowledgment. For example, "This work was supported in part by the U.S. Department of Commerce under Grant BS123456."

Dr. Bernardo Tabuenca is Assistant Professor at Information Systems Department, Technical University of Madrid, Calle Alan Turing s/n, 28031 Madrid, Spain. E-mail: bernardo.tabuenca@upm.es age [15] and the number of people in the classroom [16], [17], room acoustics (i.e., furniture distribution [18], reverberation [19]-[21]), proximity to sources of noise (e.g., neighboring classrooms [22]-[24], road traffic [25]-[27], or aircraft traffic [7], [26], [28], [29]). These factors are even more determinant in students with hearing impairment, autism spectrum, or auditory processing disorder [30], [31].

Different studies show that noise in the classroom can adversely affect different aspects: a) speech recognition and listening comprehension [32]-[36]; b) concentration [37]; c) vocal health [38]-[44]; d) hearing loss or hearing impairment [31], [45], [46]; e) bad sleep [47]; f) mental fatigue [41], mental health and stress reactions [48]-[50]; g) academic engagement or dropout rates [51]-[53]; h) annoyance, inattentiveness, or task orientation ratings[53].

The American National Standards Institute created the Acoustical Performance Criteria, Design Requirements and Guidelines for Schools standard [54]. Through specific design requirements and acoustical performance criteria, the standard aims to create a classroom environment that optimizes speech understanding. In this context, it is important to enable real-time and objective measurements to support teachers and students to moderate the noise closer to the best learning conditions in the classroom. Ubiquitous technology can play a key role supporting students and teachers in the competence of learning to learn, as well as promoting awareness about their learning processes and the best conditions for learning [55]-[57]. Unfortunately, classrooms are not always equipped with the

Dirk Börner is project manager and senior developer at the Intelligent Enterprise Technology unit of SAP SE, Chemnitzer Str. 48, 01187 Dresden, Germany, E-Mail: dirk.boerner@sap.com

Prof. Dr. Marco Kalz is Full Professor of Technology-Enhanced Learning at the Heidelberg University of Education, Im Neuenheimer Feld 561, 69120 Heidelberg, Germany, E-mail: kalz@ph-heidelberg.de 
necessary sensors and actuators to raise awareness, and to foster reflection on suitable levels of noise for learning.

The paper is structured as follows. In this section we review the empirical related work to explore 1) the technology used to capture noise (sensors) and to provide feedback (actuators) in the classroom, and 2) to define and review previous work on ambient learning displays. The study is theoretically grounded, and the hypotheses of this research are enumerated. In section II we describe the experiment, we analyze, and discuss the results. Finally, conclusions on the basis of the lessons learned and the related work are drawn.

\section{RELATED WORK}

\section{A. Automated noise feedback in classrooms}

Nowadays, smart classrooms are evolving with the help of Internet of Things (IoT) technology and are becoming environments able to sense and adapt to the student and teacher's needs. IoT is widely considered the next step towards a digital society where objects and people are interconnected and interact through communication networks. Recent work shows IoT smart classrooms built to provide visual feedback on the quality of lectures held there [58]. Patterns of students' behavior were recognized based on the recordings of one camera (positioned in the corner of the classroom) and one broadband microphone (positioned in the middle of the classroom). Patterns were mapped to computer actions using machine learning algorithms, and then displayed on the LED lamp using a corresponding graphic (i.e., a smiley or a sad face) for students' perceived interest or disinterest in parts of the lecture. Using the IoT LED lamp, lecturers could in almost monitor the level of students' attention in real-time.

Lyk and Lyk [59] designed the robot Nao, an authority figure to help the teacher moderating the noise level in the classroom. In the experiment the robot asked the children if they could be quieter once the noise level reached a certain value. The robot did not only have an immediate effect on the noise level, but also raised the general awareness on the level of noise.

The decreasing cost of electronic components in the last years is facilitating the creation of commercial products to reduce noise levels in schools, open plan offices, hospitals, or industrial companies. One example is a recent study [60] that explored the effect of visual feedback on classroom noise levels using a SoundEar II device that monitors noise levels in real time with feedback on intensity levels using a 3-colors lighting system: green, yellow, and red. Noise levels from three primary school classrooms were measured over 36 hours of classroom activities. Visual feedback resulted in a $1.4 \mathrm{~dB}$ reduction in the average noise levels.

Using a non-commercial set of wired microphones, Prakash et al. [61] featured a similar 3-color feedback approach concluding significant differences among all the groups before and after the installation of the device. In this case, teachers were instructed to take an action whenever the LED is not green (i.e., Yellow: Teacher must advise students that they should be concerned about the noise; Red: Teacher should be concerned about noise interference as continuous exposure may harm the teaching learning environment). Both commercial [60] and non-commercial solutions [61] were calibrated to provide the feedback according to the noise levels specified by the American standard [54].

Bridging the research on ambient displays to provide feedback and noise within classrooms, Reis and Correia [62] created a serious game to raise awareness on a specific topic, and introduced characters presented on ambient displays that changed their appearance depending on the level of noise. The reported results suggest that the noise means measured by the microphone in 4 groups decreased 39\%,26\%,21\%, and 5\% respectively as a result of the intervention. However, the gamification did not have an impact.

\section{B. Ambient Learning Displays (ALD)}

Wisneski et al. [63] introduced ambient displays in the context of ubiquitous computing as a new approach interfacing people with online digital information moved off the screen into the physical environment manifesting itself as subtle changes in form, movement, sound, color, smell, temperature, or light. Instead of demanding attention, this approach exploits the human peripheral perception capabilities. The displays situated and interacting in the close proximity are an addition to existing personal interfaces in the foreground, while the user attention can always move from one to the other and back [64].

The concept of ambient learning display was recently introduced by Börner et al. who reviewed [65] the use of ambient displays to provide situational awareness and give feedback in a learning context. Among other results, the authors concluded that feedback with low cognitive load, delivered immediately after a potentially wrong behavior was the most effective implementation of feedback for an ambient display. Later, authors presented a formative [66] study using "Energy Awareness Displays" to make hidden energy consumption data visible and accessible for people working in office buildings. The main goal was to provide situated feedback when taking individual consumption actions at the workplace with the goal to change their consumption behavior as well as the attitudes towards energy conservation. In their following research [67], the authors evaluated the impact of those displays finding no clear evidence that they might have influenced on learning outcomes or lead to pro-environmental behavior change. More recently [64], the authors evaluated an ALD that presented guidelines for first responders in cases of cardiac arrest. The ALD was enhanced with a custom-built sensor to measure user attention and trigger interruptive notifications. The results provided evidence that such a display design could attract and retain attention in such a way that the acquisition of knowledge improved. Inspired on that research, we define an ambient learning display as an indicator reporting changes of the learning context seamlessly integrated in the environment of the user.

Previously, several related studies had examined the provision of visual feedback in ambient displays. Kappel and Grechenig [68] proposed an ambient display integrated in shower to promote the conservation of water. Specifically, for 
the conservation context they argued that feedback was most effective if it was immediate, close to the source of consumption, and related to a specific goal. Ambient displays can function as persuasive devices that provide a constant flow of consumption information in the periphery of the consumers' attention in an aesthetically pleasing manner. Finally, the evaluation showed that this type of ambient feedback was effective in fostering the desired sustainable behavior change. Similarly, Ham and Midden [69] argued that ambient persuasive technology was more effective than feedback demanding direct attention. In their study the authors compared the use of color changes of light related to actual consumption intensity and concluded that light was particularly suitable to provide feedback and requires lower processing time and thus cognitive load. In a follow-up study the authors examined the effect of different color codes for light as feedback and found that strongly associated color codes (i.e., red and green for high and low energy consumption) had stronger persuasive effects in terms of energy conservation and also demanded lower cognitive load [70].

Putting more emphasis on aesthetic aspects Nakajima and Lehdonvirta [71] presented several case studies focusing on behavior change by providing personalized feedback using so called persuasive ambient mirrors. These displays basically reflected the user's current behavior, attitudes, status, or performance. The authors argued that supporting users with suitable feedback of their potential choices and actions could result in significant changes in their habits.

This paper introduces a quasi-experimental study that has employed an ambient learning display to measure noise levels and to provide feedback to teachers and learners in a secondary school. The goals of the study were: 1) to evaluate the effectiveness of an ALD raising awareness about noise in the classroom. Perception of noise from students might be different from the perception by teachers. Hence the accuracy of perceived level of noise will be taken as a measurement of noise awareness; 2) to collect data and to analyze the impact of the ALD on the perception and behavior of teachers and learners; 3) to raise awareness among students and teachers about the relationship between noise and learning performance in classrooms.

The novelty of this study is threefold: 1) this study presents the first IoT wireless architecture using a mobile device to sense and report noise levels to an ALD in a secondary school; 2) this is the first study providing visual feedback within the range of 512 different colors adapted to real-time noise levels; 3 ) to the best of our knowledge, this is the first study investigating how to decrease noise levels in classrooms calibrating the feedback according to the specific characteristics of the classroom where it is evaluated.

\section{FRAMEWORK AND HYPOTHESE}

\section{A. Theoretical framework}

The study has the goal to analyze the relationship between ambient noise in the classroom and (perceived) learning and the potential to influence this relationship with an ambient learning display. Theories and (cognitive) models exploring noise in the classroom are trying to develop a better understanding of different learning processes and the impact of noise on them. Examples of these theoretical approaches include the HURIER model [72] which recognizes the complexity of listening and defines six behaviors involved in the listening process: hearing; understanding; remembering; interpreting; evaluating and; responding. A recent review [73] identifies student and classroom characteristics related to students' listening skills highlighting the relevance of noise for adequate listening conditions in classrooms. Recent research suggests that noise may affect memory by impairing the quality with which information is stored in the memory [27], [62]. Woolner and Hal [74] reviewed the weight of evidence in the relation between noise and learning. Their study concludes that noise over a given level does appear to have a negative impact on learning.

In the present work, we investigate whether automated visual feedback can moderate noise towards learning under better conditions. Noise levels are usually moderated by teachers asking their students to shut up and listen in the course of a lecture, or to decrease their voice volume when working in groups. Nonetheless, noise can be moderated by alternative automatic systems. [59] investigated whether the robot Nao could help the teacher keep the sound volume at an acceptable level. The robot was configured to say 3 different sentences to avoid repeated auditory feedback: "Can you please stop making so much noise. My head hurts", "Be quiet" or "You are a bit loud, could you be more quiet?." When the noise level rose to a high level and the Nao asked if they would be quiet, there was an immediate reaction of total silence. Likewise, automated visual feedback systems can also moderate the noise levels in the classroom. Van Tonder [60] concluded that most teachers were able to keep classroom noise to a minimum with the help of SoundEarII. Similarly, [13], [61], [75] were able to reduce the average level of noise when the used the visual feedback system.

In the study we rely on perceived learning effects instead of measures of learning effects due to the following reasons: 1) time and space in the curricula are usually tight, and introducing interventions can be already time consuming; 2) it is difficult to develop additional metrics to assess knowledge levels adapted to the period of time when the intervention occurs. Selfassessments or perceived learning effects offer the potential to reduce the burden of developing tests to determine whether the desired knowledge has been gained as a result of participation in a course or training intervention. Sitzmann et al. [76] conducted a meta-analysis to clarify how closely selfassessments are related to cognitive learning outcomes. The authors found that perceived-learning's strongest correlations were with motivation and satisfaction, whereas the relationship between perceived-learning and cognitive learning was moderate. Nonetheless, their results conclude that selfassessments of knowledge have a key role in the learning process and that learners benefit from having an accurate understanding of their knowledge levels [77]. In this particular 
case, secondary school students need to build lifelong learning habits and critically evaluate their own learning performance [78].

\section{B. Hypotheses of the Experiment}

The study introduced in this paper builds upon these findings to investigate the effectiveness of visual feedback provided by a digital device, to raise awareness of noise in the classroom in real time. Consistently, we have formulated the following research questions (RQ):

RQ1. What are the effects of providing real-time feedback about the noise in secondary school classrooms using an ALD?

RQ2. Is there any correlation between noise and perceived learning performance?

The following hypotheses $(\mathrm{H})$ were elaborated to investigate the research questions: H1a). Noise levels will decrease when classrooms are equipped with an ALD reporting visual feedback about the noise. H1b). Noise fluctuation will decrease when classrooms are equipped with an ALD configured to moderate the levels. H1c). Visual feedback will help students and teachers to become aware of the noise in the classroom. H1d). Perceived learning performance will increase as a consequence of using an ALD reporting visual feedback about the noise. H1e). Teachers and students will perceive the ALD as a useful tool to support learning in the classroom. H2). Perceived learning performance decreases as noise increases.

\section{METHOD}

In this work, we aimed at reducing the noise levels in secondary school classrooms under the specific conditions where each group normally performs its lectures using an ALD. Therefore, the current study investigated the effect of a realtime visual feedback system for noise levels in the classroom in a sample of Spanish public secondary school.

\section{A. Participants}

A total of 198 students mean age 14.5 (49\% female) from 12 different groups ( $\mathrm{M}=14.5$ students) enrolled in the subject "Technology", and their respective teachers were invited to participate in a study that took place in a secondary school. The subject "Technology" is taught from 2nd to 4th course of secondary education in Spain. The experiment comprised 24 sessions of 50 minutes.

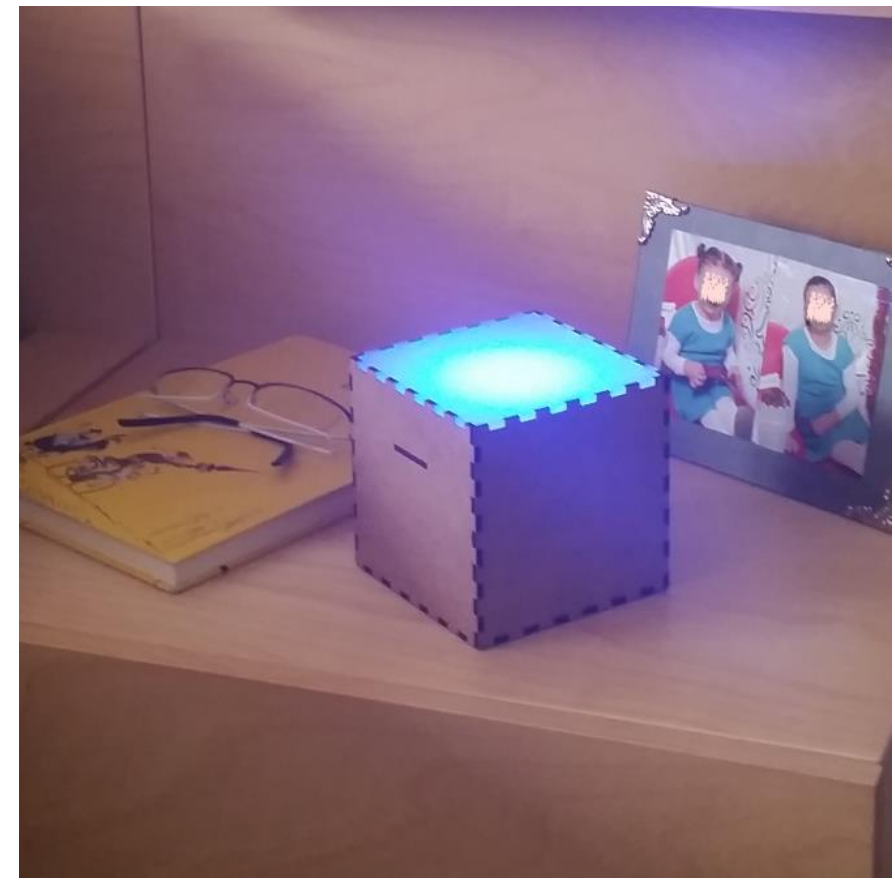

Fig. 1. Feedback cube.

Materials

The following devices were devised, designed, assembled and programmed for this study:

Ambient Learning Display: Feedback Cube

Figures that are meant to appear in color, or shades of black/gray. Such figures may include photographs, illustrations, multicolor graphs, and flowcharts. The Feedback Cube (see Fig. 1) is an ALD built on an Arduino microcontroller that provides visual and audio feedback. For the prototypical system design a cubic shape was chosen. As solid threedimensional objects, cubes represent familiar physical structures that can be utilized for tangible manipulation, spatial interaction, or expressive representation [79]. The exterior of the cube prototype was made from high-density fiberboard and semi-transparent Plexiglas, whereas five sides of the cube are opaque and only the top is semi-transparent. The interior comprises a set of components as well as the necessary hardware to operate them. The cube has an edge length of $100 \mathrm{~mm}$, so that all components fit in, while still ensuring a reasonable size for tangible interaction. Further details on the design of the Feedback Cube are reported in a previous publication [80].

The LEDs used can display 16777216 colors at 256 brightness levels. The ring of 16 LEDs can be controlled individually, which allows programming visual patterns and effects such as fading, blinking, or color transitions (see Appendix I). The mini speaker used can reproduce programmatically created audio patterns and effects such as playing single tones, complex melodies, or even encoded audio files.

This study aimed at exploring the effects of an ALD providing a smoother and seamless feedback working from the background of the classroom (see Fig. 2). Therefore, the ALD was configured to represent one of the 512 colors in the gradient 
between the green and the red color (with yellow in the middle). Likewise, the color represented in the ALD was calculated based on the 5 last samples to alleviate peaks and consequently to represent a gentler feedback. The color of the ALD was refreshed every second to show softer transitions.

The Arduino has a Wi-Fi interface that enables direct communication between the microcontroller and other devices in the local area network. An HTTP server and a web service (Application Programming Interface) were developed to facilitate the communication between the ALD and the mobile device. The API features and the commands are listed in Appendix I (see Table V).

\section{1) Sensor mobile app: Noise Reporter}

The Noise Reporter is a decibel meter mobile application developed for this study. The mobile app uses the device's microphone to detect sound and convert it into a decibel value. The mobile was placed in such a way that it could absorb the average noise of the classroom (see appendix II).

This Android app uses the microphone of the mobile phone to 1) collect noise samples, 2) buffer them into a local database, 3 ) calculate the average decibels of the last $n$ seconds in the buffer to alleviate peaks, 4) translate the average decibels into a color gradient ranging from a minimum threshold (i.e., green) to a maximum threshold (i.e., red), and finally 5) requests a color to the ALD using the API (Appendix I). The tool was configured to loop these 5 steps every second. The open source code for the mobile sensor app is available online to facilitate further iterations of the experiment (https://github.com/btabuenca/NoiseReporter).

\section{2) Wireless router}

The router is used to create a local network comprising the ALD and the mobile device via WI-FI connection.

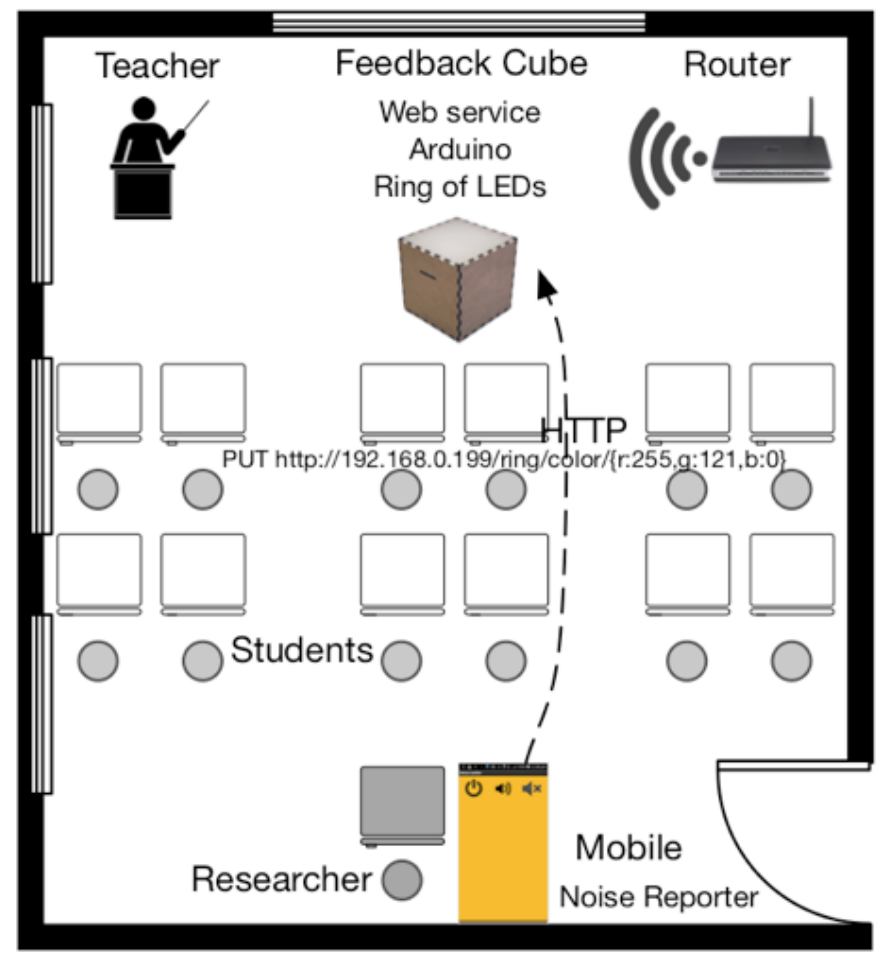

Fig. 2. Technical setup used to deploy the ALD in the classroom.

\section{B. Design of the Experiment}

The study builds on a quasi-experimental design where students are not randomized. The sampling strategy was performed based on their initially assigned groups at the educational institution at the beginning of the course (i.e., classroom, teacher, and colleagues). The experiment consists of a one-group pretest posttest design, in which the baseline measurement is used as a control measurement.

The experiment was performed on 12 different groups (i.e., 198 students and 4 teachers) in two iterations (i.e., 24 sessions). The first iteration was performed without using the ALD resulting in a baseline measurement of objective noise levels per classroom. In the second iteration, the noise samples collected during the first iteration were used as input to calibrate the thresholds in the mobile app according to the specific results obtained on each group. At the end of each session, teachers and students could rate the usefulness of the ALD. Measurements of the following variables were collected in both rounds:

\section{1) Dependent variables}

Noise samples were collected using three different inputs: First, the objective measurement (NOM). Samples of noise were collected (every second) along the course of the sessions using the microphone of the mobile phone. Secondly, students' perceived noise (NPS). Individual responses from students were collected in a questionnaire at the end of the sessions to gather their perception of noise in a 7-point Likert scale ranging from "very low" (1) to "very high" (7). Third, teachers" perceived noise (NPT). A post-questionnaire was completed at the end of the session to gather teacher' perception of noise in a 7-point Likert scale ranging from "very low" (1) to "very high" (7).

Perceived learning samples were collected using two different inputs: First, students' perceived learning performance 
(LPS). A post-questionnaire was completed at the end of the session to gather students' perception of learning performance in a 7-point Likert scale ranging from "very low" (1) to "very high" (7). Secondly, teacher's perceived learning performance (LPT). A face-to-face survey at the end of the session gathered teachers' perception of students' learning performance during the session in a 7-Likert scale ranging from "very low" (1) to "very high" (7).

\section{2) Independent variable}

Noise (objective and perceived) and learning performance (perceived) were expected to vary with the intervention of the ALD providing feedback during the experimental session (independent variable). Additionally, the cube was expected to trigger different interactions between teacher and students. Hence, visual feedback (Yes/No) is considered the control variable.

\section{Procedure}

The ALD was presented to the teachers of the Department of Technology focusing on two key objectives: 1) an experiment that would help them to decrease the noise level in their classrooms; 2) a practical experience to show students how to assemble microcontrollers, sensors, actuators, and mobile devices towards performing an action within their own learning context.

The participation in the experiment was voluntary and not remunerated. Students were informed that the data gathered during the experiment was anonymous and the participations would not affect their grades. All teachers at the Technology Department approved to participate. The data was collected and carefully treated considering the existing policies in the autonomous region.

\section{1) Control session}

The baseline measurement was performed for one week. The researcher collected noise samples using the mobile app during the sessions and gathered the questionnaires at the end of the sessions.

\section{2) Experimental session}

The feedback intervention was performed during the second week of the experiment in the same classroom, at the same day of the week, at the same time, and with the same teacher. The noise samples collected during the baseline measurement (see Fig. 3) were used to calibrate the device, and consequently to provide adapted feedback. Hence, the mobile app was configured assigning to the maximum threshold, the value of the upper quartile (e.g., -0.996 in Fig. 3). Likewise, the minimum threshold was configured with the value of the lower quartile (e.g., -9.827 in Fig. 3). At the start of each experimental session, the researcher placed the ALD ensuring that the light was visible to everybody and introduced its function to the students. They were not alerted that the noise would be collected from the mobile device (not from the cube). During the experimental sessions, the Noise Reporter collected noise samples and reported the samples to the cube. The researcher gathered the questionnaires at the end of the session.

One week after the experimental sessions the researcher organized a brainstorming session with the teachers to discuss the experience and explore the potential of the ALD. Additionally, a joined lecture with all students was organized to show them the components used, basic programming function in Arduino and Android, and initial conclusions of the results obtained.
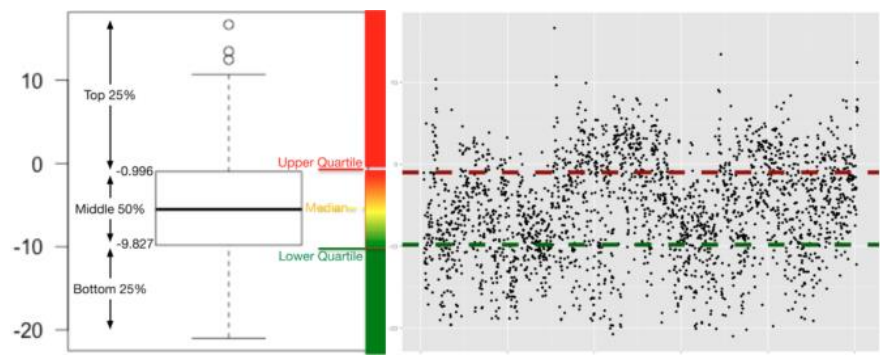

Fig. 3. ALD's calibration.

\section{Data Analysis}

Participants in the study finally involved 198 students and teachers who voluntarily accepted completing the questionnaires after the control and experimental sessions (see samples NPS, NPT, LPS and LPT in Table I). The mobile app collected 60612 samples in 24 sessions (see NOM in Table I).

Questionnaire data were transcribed from paper to MS Excel format and exported to comma-separated (CSV) files. The noise samples collected with the mobile device were exported from the SQLite database of the Noise Reporter to CSV files. All these CSV files were imported as datasets and analyzed using R Studio (v0.98.1102). Notes taken during the sessions were used to understand data obtained and to reinforce the conclusions reported in the manuscript.

Reliability tests were performed to validate whether these samples consistently reflect the constructs that they are measuring: noise and perceived learning. The scores obtained demonstrated adequate consistency of scores with $\alpha=.78$. Nunnaly et al. suggest that a reliability score of .70 or higher is acceptable [81]. When examining the internal consistency of scores by variable (see Table I), values for Cronbach alpha revealed acceptable consistency levels for the noise measurements $(\alpha=.75)$ whereas the perceived learning performance by teachers' measurements concluded in weak consistency $(\alpha=.60)$ justified by the low number of teachers that participated in the experiment.

\section{RESULTS}

This section presents the results from the quantitative analysis. These results are further discussed and interpreted in the conclusions section together with the observations made during the experiment.

\section{A. Effects of Using the ALD}

In H1a we hypothesized that the noise would decrease across all groups in the classrooms from the control to the experimental session as an effect of the real-time feedback supplied by the ALD. The results obtained contrasting the mean noise from the control session $(\mathrm{M}=-3.39 ; \mathrm{SD}=6.29)$ with the 
experimental session $(\mathrm{M}=-3.47 ; \mathrm{SD}=6.51)$ support our hypothesis. An analysis of variance (ANOVA) test was performed with the aim to determine whether the observed difference is significant. Previously, a Shapiro-Wilk test was conducted with to confirm the normal distribution assumption required to perform the ANOVA test. The p-values higher than .05 confirm that samples are normally distributed and consequently the assumption is verified. The results of the ANOVA test show that the difference between the means obtained is not significant, and the hypothesis cannot be confirmed (see Table I).

TABLE I

INTERNAL CONSISTENCY, NORMALITY OF DISTRIBUTION, ANOVA AND MEANS

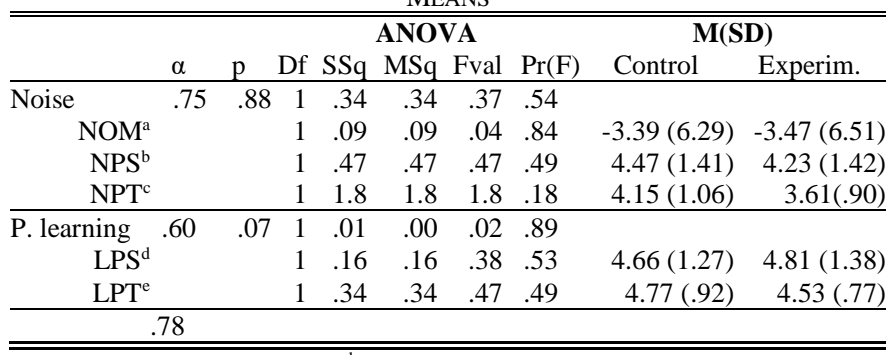

${ }^{\mathrm{a}}$ Noise Objective Measure; ${ }^{\mathrm{b}}$ Noise Perceived by the Students; ${ }^{\mathrm{c}}$ Noise Perceived by the Teacher; ${ }^{\mathrm{d}}$ Perceived Learning performance by Students;

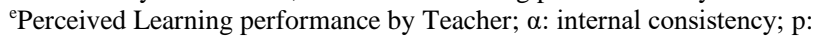
normal distribution; $\operatorname{Pr}(>\mathrm{F})$ : ANOVA.

As there are multiple factors affecting the noise levels in the classroom, the hypothesis was evaluated for each individual group with the aim of exploring concrete factors. The noise samples obtained during the control session were taken as a benchmark to classify the sessions into 7 noise levels ranging from Very High (Max. $M=.72$ ) to Very Low (Min. $M=-9.23$ ). The boxplots presented in Fig. 4 contrast control and experimental sessions. The noise decreased in 6 out of 12 groups (2A, 2B, 3A, 3D, 4, and BT1). Indeed, Table II shows that the treatment was successful for the groups ranked as quieter. On the contrary, the treatment had an inverse effect in the groups initially ranked as noisier (2CDBil, 2EF, 3B, 3C, 3 Div, and 4Div). 4 out of the 6 groups where the treatment was successful (noise decreased), had noise means below the overall mean $(\mathrm{M}=-3.42$ decibels; $\mathrm{SD}=6.39 ; \mathrm{Max}=21.55$; $\mathrm{Min}=-$ 21.86), whereas 5 out of the 6 groups whose noise mean increased, had noise means above the overall mean. An ANOVA test determined that the observed differences are not significant. These measurements were taken considering that the ALD would play the same role in all 24 session decreasing the noise. However, some sessions (e.g., workshops) were scheduled with different activities (e.g., saw wood) between the control and the experimental condition that affected the noise data sample analyzed for this hypothesis.

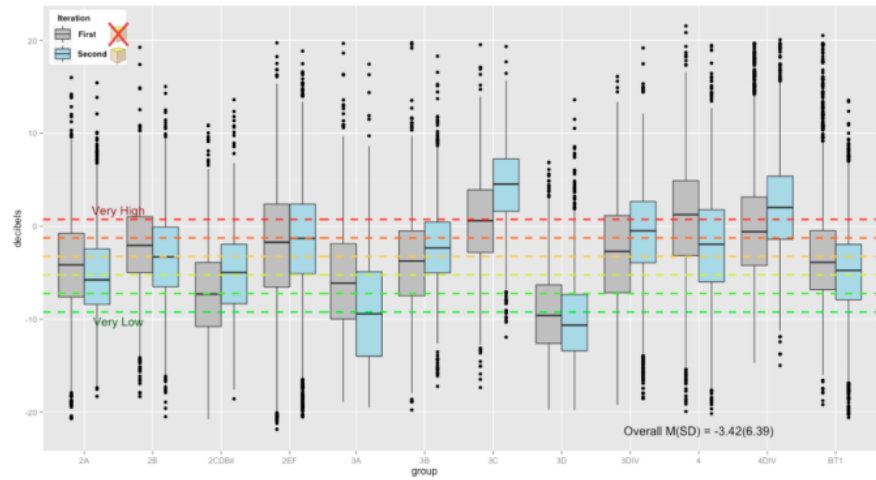

Fig. 4. Classification of sessions by noise level and contrasts of noise means by group.

As the ALD was configured to display a red color whenever the noise samples were above the upper quartile, and green when the samples were below the lower quartile, in hypothesis $1 \mathrm{~b}$ we considered that students and teachers would moderate their volume to avoid the red color, and consequently the measurements in the experimental session would fluctuate less with respect to the mean measurement. The standard deviation is used to quantify the dispersion during the control and experimental sessions. The analysis of the groups shows that 10 groups (out of 12) are consistent with our assumption. An ANOVA test determined that the observed differences are not significant. These results are based on 2 measurements in 12 lectures. Based on the observations during the sessions, the fluctuation of noise decreased when the activities were guided and the teacher interacted with the ALD. More repetitions of the measurements under these conditions might help understand the potential of the ALD to decrease noise fluctuations.

In hypothesis 1c we considered that visual feedback would help students and teachers to become aware of the noise in the classroom. Hence, we expected that students and teachers would report more accurate measurements of noise when they have real time feedback as a reference. The differences between perceived noise and the objective noise measurements are taken as an indicator (See Accuracy in Table II). Our assumptions are true whenever this difference decreases from the control to the experimental session. The overall means show that students improved the accuracy of their estimations from the control sessions $\mathrm{M}(\mathrm{SD})=.63(0.24)$ to the experimental session $\mathrm{M}(\mathrm{SD})$ $=.24(1.45)$. An ANOVA test determined that the observed differences are significant $(\operatorname{Pr}(>\mathrm{F})<.001)$. Analyzing the groups separately, the results show that the students from 8 groups (out of 12) reported more accurate estimations in the experimental session, whereas only 4 reports from teachers (out of 12) improved the accuracy of their noise estimations. At the start of each experimental session, the researcher introduced the function of the ALD to the students. Based on the observations, most of the teachers did not rekindle or adjust its function anymore during the lecture and probably the ALD turned invisible for many students after some minutes. These results might be more conclusive the when teacher recall the role of the ALD during the course. 
TABLE II

SUMMARY OF NOISE MEASURES OBTAINED BY SESSION

\begin{tabular}{|c|c|c|c|c|c|c|c|c|c|c|c|}
\hline & \multicolumn{3}{|c|}{ NOM $^{\mathbf{a}}$} & \multicolumn{2}{|c|}{ NPS $^{\mathbf{b}}$} & \multicolumn{2}{|c|}{ NPT $^{\mathrm{c}}$} & \multicolumn{4}{|c|}{ "Accuracy [1..7] } \\
\hline & & & & Stuc & dents & Teac & cher & Stuc & dents & Teac & cher \\
\hline & $\mathrm{M}$ & $\begin{array}{c}\text { Ct. } \\
\text { M(SD) } \\
\end{array}$ & $\begin{array}{c}\text { Ex. } \\
\text { M(SD) } \\
\end{array}$ & $\begin{array}{c}\text { Ctr. } \\
\text { M }\end{array}$ & $\begin{array}{c}\text { Exp. } \\
\text { M } \\
\end{array}$ & $\overline{\mathrm{Ct}}$ & Ex. & \begin{tabular}{|c} 
Ctr. \\
M \\
\end{tabular} & $\begin{array}{c}\text { Exp. } \\
\text { M } \\
\end{array}$ & Ctr. & Ex. \\
\hline $2 \mathrm{~A}$ & -4.70 & $-4.32(5.1)$ & $-5.32(4.6)$ & 3.53 & 4.47 & 4 & 4 & 0.10 & 1.52 & 0.59 & 1.05 \\
\hline $2 \mathrm{~B}$ & -2.71 & -2.1 & -3.39 & 5.06 & 4.31 & 5 & 5 & .76 & 0.54 & 0.70 & 1.23 \\
\hline $2 \mathrm{C}$ & -6.32 & $-7.53(5.2)$ & $-5.07(4.6)$ & 3.00 & 4.38 & 3 & 4 & 0.99 & 1.32 & 0.99 & 0.94 \\
\hline $2 \mathrm{E}$ & -2.04 & $-2.26(6$ & $-1.58(6.3)$ & 4.71 & 4.55 & 5 & 3 & 0.47 & 0.02 & 0.76 & -1.53 \\
\hline $3 \mathrm{~A}$ & -7.32 & & & 5.00 & 2.67 & 6 & 2 & 2.16 & 1.26 & 3.16 & 0.59 \\
\hline $3 \mathrm{~B}$ & -3.30 & & -2 & 4.72 & 3.94 & 2 & 3 & 1.27 & -0.32 & -1.45 & -1 \\
\hline $3 \mathrm{C}$ & -2.13 & & & 6.27 & 6.23 & 5 & 5 & 0.90 & & -0.37 & -2 \\
\hline $3 \mathrm{D}$ & -9.54 & -9.2 & -9.9 & 4.27 & 3.18 & 4 & 4 & 2.98 & 2.18 & 2.71 & 3.00 \\
\hline $3 \mathrm{DI}$ & I -2.17 & $-3.38(6$ & -0.85 & 4.00 & 3.00 & 3 & 2 & 0.23 & -1.84 & -0.77 & -2.84 \\
\hline 4 & -0.46 & $0.72(6$ & -2.04 & 4.81 & 4.82 & 4 & 4 & -0.69 & 0.49 & -1.50 & -0.33 \\
\hline 4DI & $\begin{array}{l}\text { I } \\
0.84\end{array}$ & $-0.05(5$ & 2.20 & 4.92 & 5.08 & 5 & 4 & -0.26 & 1.05 & -0.18 & -2.13 \\
\hline BT & -4.11 & $-3.24(5.5)$ & $-5.13(5.0)$ & 2.75 & 3.44 & 4 & 3 & -1.08 & 0.41 & 0.17 & -0.03 \\
\hline
\end{tabular}

In H1d we hypothesized that students would report increased perceived learning performance because of the moderation in the noise performed by the ALD. The results illustrated in Table III show that students' perceived learning performance improved from the control to the experimental session in 9 groups (out of 12 groups). These conclusions should be further explored as the ANOVA test concluded not significant differences $(\operatorname{Pr}(>F)>.1)$. Based on the observations, long-term studies fostering policies to make of noise an active focus of attention might lead to improved learning perceptions.

In H1e we hypothesized that students and teachers would perceive the ALD display as a useful approach to support suitable noise levels towards learning. The reports from teachers and students to the statement "The Cube helps to moderate the level of noise in the classroom towards learning in this group" at the end of the experimental session are taken as indicator. This item was analyzed with the help of a 7-item Likert scale ranging from "7.- Completely agree" to "1.Completely disagree" considering values above 4 as useful. Lower levels of usefulness associate with noisier classrooms. The results presented in Table III show that the students from 11 groups (out of 12) considered that the ALD was useful. Consistently, the noisiest group (3C) was the only one that reported a mean value below $4(\mathrm{M}=3.22)$. Uniformly from teachers' perspective, only the ones from the two noisiest groups (3C and 4 DIV) reported values below 4 . These perceptions are consistent with the ones presented in Table II. Overall, teachers $(\mathrm{M}=5 ; \mathrm{SD}=1.22 ; \mathrm{n}=12)$ rated slightly above students $(\mathrm{M}=4.75 ; \mathrm{SD}=1.73 ; \mathrm{n}=198)$ estimating the usefulness of the ALD. Based on the discussion with teachers, all agreed that the ALD might be more useful whenever it would be regular actor in the classroom.
TABLE III

Summary of PERCEIVEd LEARNING PERFormanCE AND USEFULNESS MEASURES OBTAINED BY SESSION

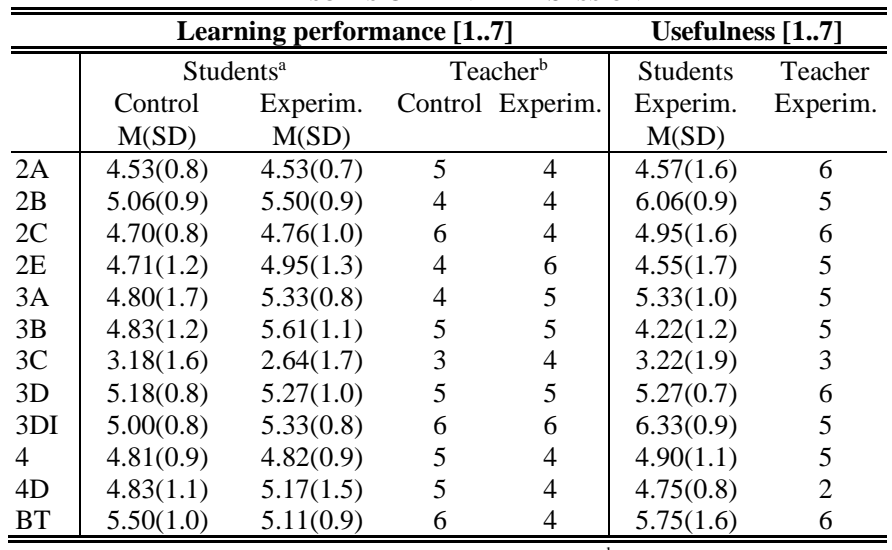

${ }^{\mathrm{a}}$ Learning performance perceived by Students and ${ }^{\mathrm{b}}$ Learning performance perceived by the Teacher are scaled [1..7] so that "very low learning performance" $=1$, and "very high learning performance" $=7$.

\section{B. Correlation between Noise and Learning Performance}

In hypothesis 2 we expected that the noise level in the classroom would be negatively correlated with perceived learning performance. A Pearson's correlation was run to determine the relationship between the variables measured during the study (see Table IV). Pearson indicates the strength of the linear relationship between two variables for which the values range between $-1<0<1$. The values closer to $1(-1)$ depict a stronger positive (negative) correlation, meaning that the second variable tends to increase (decrease) when the values of the first value are increased and vice versa. The closer the values are to 0 , the weaker the correlation is. A p-value less than 0.01 is taken as indicator for significant correlations. We can verbally describe the strength of the correlation using the guide that [82] suggests for the absolute value of $\mathrm{r}$ (Strength: .00-.19 "Very weak"; .20-.39 "Weak"; .40-.59 "Moderate"; .60-.79 "Strong"; .80-1.0 "Very strong").

The results from the correlation analysis show that there is a strong negative correlation between student's perceived learning performance and student's perceived noise $(r=-0.67$; $\mathrm{p}=0.0002053)$. Likewise, there is a moderate negative correlation between student's perceived learning performance and the objective measurement of noise $(r=-0.46 ; p=0.018)$. As a consequence, these results confirm our hypothesis (See Fig. 5).

TABLE IV

CORRELATION ANALYSIS

\begin{tabular}{cccccc}
\hline \hline $\mathbf{r}$ & NOM & NPT & NPS & LPT & LPS \\
\hline \hline NOM $^{\mathrm{a}}$ & 1 & & & & \\
NPT $^{\mathrm{b}}$ & 0.26 & 1 & & & \\
NPS $^{\mathrm{c}}$ & $0.65^{*}$ & $0.57^{*}$ & 1 & & \\
LPT $^{\mathrm{d}}$ & -0.18 & $-0.60^{*}$ & $-0.55^{*}$ & 1 & \\
LPS $^{\mathrm{e}}$ & -0.46 & -0.38 & $-0.67^{*}$ & 0.43 & 1 \\
\hline \hline
\end{tabular}

${ }^{\mathrm{a}}$ Noise Objective Measure; ${ }^{\mathrm{b}}$ Noise Perceived by the Teacher; ${ }^{\mathrm{c} N o i s e}$ Perceived by Students; ${ }^{\mathrm{d}}$ Perceived Learning performance by Teacher; ${ }^{\mathrm{e}}$ Perceived Learning performance by Students; *Correlation of significance ( $\mathrm{p}$ $<0.01)$. 


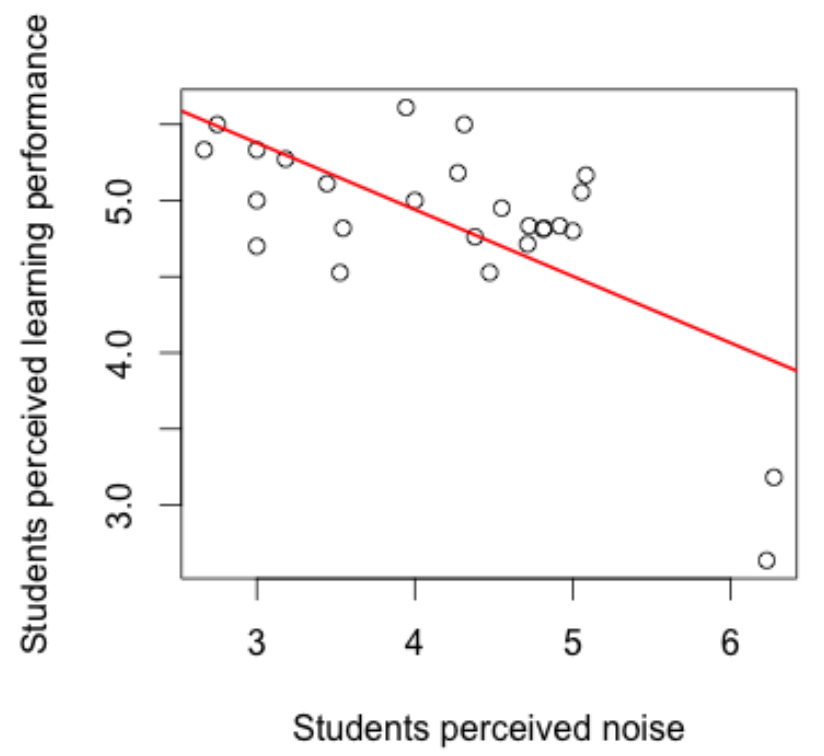

Fig. 5. Strong negative correlation between perceived noise and perceived learning performance.

\section{DISCUSSION}

The results reported in this study provide evidence of the capability of an ALD to moderate the noise levels in classrooms. The ALD presented in this work was not equally effective in all the groups. The ALD was effective for quieter groups, whereas it had a reversed effect for the noisiest groups. Combining the quantitative statistics with observational data, results point to the possibility that social and instructional aspects could have mediated the effectiveness of the ALD.

Teachers of the noisier groups were more tolerant to noise and allowed parallel talks or interactions among students while the teacher was giving the lecture. In this line, students and teachers broadly agreed on the usefulness of the ALD, with the exception of the two noisiest groups that rated it negatively. The "freedom" facilitated deliberate attempts to turn the ALD into red color by coughing, banging on the table, clapping hands, or celebrating with an uproar when they were reaching a color closer to red.

The study could also show that an ALD can help students to develop more accurate estimations of the current noise levels in their surroundings contributing to an increased awareness for noise as a condition for effective learning. The existence of the ALD can function at the same time as a proxy to remind students to calm down. Furthermore, these results have shown that the ALD was able to moderate the noise during the experimental sessions with levels that fluctuated less than the control sessions. The ALD was calibrated so that the colors were closer to green tones for low noise levels, yellow for average noise levels, and red for high noise levels. Several teachers and students reported about the connotations of using the yellow color of mean levels arguing that this color led them to think (wrongly) that the noise level was too high. In future implementations we suggest that the ALD is calibrated assigning the green color to values lower than the median, and the red color to values higher than the upper quartile.

The results obtained for hypothesis 2 indicate that there is a linear correlation between the noise level in the classroom and the perceived learning performance reported by the students. Indeed, the correlation analysis indicates that students reported higher levels of perceived learning performance when the noise level was lower. Likewise, perceived performance was lower when noise was higher. This correlation was strong with respect to the noise estimates reported by the students, and moderate with respect to the objective noise measurement collected with the sensor. The results provide evidence of the negative effects produced by the noise on the perceived learning performance from students. These conclusions rekindle the need to extend research correlating the noise measurements with actual learning performance since perceived learning performance is often considered a weak proxy for learning performance [76], [83].

The introduction of the ALD in the classrooms leads to similar behavior in all groups. Initially, the ambient display occupied the focus of the students who were attentive to color changes and deliberately made noise to explore how the ALD would react (moving the chair, coughing, or manipulating material on the table). As the session progressed, the ALD gradually lost the focus. Future studies should explore the right balance between attention to the ALD and effectiveness. Longer-term studies are needed to show if an ALD can also sustain the effects on noise leveling. Differences in effectiveness between ambient feedback and numerical feedback would be of interest to explore alternative representations.

Different factors limited the conducted research: 1) Due to connectivity problems in an experimental session the data from the 13th group had to be discarded. 2) The installation of the ALD at the beginning of each session required some minutes (approx. 5) that were not sampled in the experiment. Likewise, the last 5 minutes of the session were used to complete the questionnaires. These two interventions during the class might bias the real noise flow within the classroom. 3) Variables such as GPA (grades), personality characteristics, age, gender, or autonomous learning were not included in this study due to time restrictions and teachers' workload. Including such variables might increase the power of the analysis and consequently more effectively capture the effect of the ALD.

\section{CONCLUSION}

This study has shown that ALDs might contribute to improved perceived learning conditions moderating the noise levels in secondary school classrooms. The study has shown that the effectiveness of the ALD was dependent from the base noise levels and teaching context of each group. Various teachers indicated that the ALD would have been more effective whenever they would have interacted with it (e.g., a game policy [62], or a teacher instruction [61] ) based on the "time on red" or the "time on green". However, only one of the teachers took the initiative to interact with the ALD and temporarily stopped the lecture when it was reporting high 
noise levels and resumed the lecture when the green indicator came back. Most of the teachers let the ALD "do its job" without boosting its role as an objective indicator of the noise levels in the classroom. Hence, the effectiveness of an ALD for noise leveling is a socio-technological issue depending on the instructional embedding and role that an ALD is given by the teacher. Successive policies following the status of the ALD might lead to more effective implementations.

The brainstorming session, the comments collected, and the lessons learned during the investigation helped to identify the following factors that were not considered in the initial design of the experiment but should be considered in future research:

1) Location of the study. The location of the school can influence noise levels depending on whether it is a rural or urban area, the social and cultural aspects of the area, the weather conditions, or the number of daylight-hours in the region. For example, one of the teachers stated "... if we compare these measurements with those of other countries, certainly ours will be above the average". Another reported "... students speak very loud, and even more in this region...", whereas a student made the following comment "... I cannot avoid it, in my hometown we shout a lot ...".

2) Classroom's dimensions and acoustics (see Fig. 6 in Appendix II). Different studies have shown differences in noise samples depending on the characteristics of the space where the session takes place [15], [41]. Existing standards recommend that unoccupied classroom levels must not exceed $35 \mathrm{~dB}$ [54]. This variable should be taken in consideration when contrasting the noise from different groups in further research.

3) Microphone used. In contrast to our expectations, the observations made during the study let us conclude that the integrated microphone from the smartphone harvested remarkably well voice and non-voice frequencies such as writing on the blackboard, cars passing close to the window, hammering a nail, or cutting wood with a saw. This study was carried out by collecting samples of noise using the same smartphone (i.e., Sony Xperia S). Calibration tests performed before the experiment with different smartphones showed remarkable differences in the scale of the collected samples depending on the microphone and the phone model that was used. Therefore, it is difficult to compare the noise measurements obtained in this experiment with previous research.

4) Location of the smartphone within the classroom. The observations made during the study let us conclude that the location of the smartphone within the classroom is a relevant factor. Future studies should take this factor into account trying to locate the smartphone in an equidistant position with respect to the noise sources. Furthermore, it should be investigated whether the height at which the smartphone is placed is also relevant for measurements (i.e., on the floor, on the table, or high up near the ceiling).

5) Orientation of the smartphone/microphone. The observations made during the study let us conclude that the orientation of the smartphone with respect to the noise sources is a relevant factor. Smartphone microphones are installed in such a way as to collect the sound from the side closer to the mouth (i.e., front side at the bottom).

The conclusions discussed in this paper should be interpreted cautiously because they are based on 24 observations (sessions), reported by 198 students and only 4 teachers. Future research should explore the effectiveness of the ALD in longitudinal studies with larger groups in which the persistence of adequate levels can be explored in long term. One student stated that "... in the beginning you stare at the cube, but after one day you forget it is there...". This comment rekindles our suggestion of the need to set rules in the classroom to boost the presence of the ALD as a witness reporting and annotating the noise levels during the session. One of the teachers proposed the following rule during the brainstorming session: “... to punish (reward) with (without) daily homework when the percentage of time on red (green) exceeded 20\% of the session...".

In this research we have shown some the benefits of using ambient displays towards moderating the noise levels by contrasting a control group with an experimental group. In further research, we suggest contrasting groups using the same ALD but varying the instructional strategies to embed the ALD into teaching activities and to work with rewards for coconstructing a productive learning atmosphere in classrooms.

\section{APPENDIX I}

TABLE V

ALD'S WEBSERVICE API

\begin{tabular}{l|l|l}
\hline \hline Method & Path & Description \\
\hline \hline PUT & /ring/on/ & $\begin{array}{l}\text { Turns the LED strip on } \\
\text { https://vimeo.com/122884537 }\end{array}$ \\
\hline PUT & /ring/off/ & $\begin{array}{l}\text { Turns the LED strip off } \\
\text { https://vimeo.com/122884536 }\end{array}$ \\
\hline PUT & /ring/fade/ & $\begin{array}{l}\text { Color starts fading. The fading } \\
\text { parameters (number, delay) are } \\
\text { provided as a JSON object: }\{\text { "n": x,"d": } \\
\text { x }\} \\
\text { Fade slow five times: } \\
\text { https://vimeo.com/122884370 }\end{array}$ \\
& & $\begin{array}{l}\text { Fade fast ten times: } \\
\text { https://vimeo.com/122884369 }\end{array}$ \\
\hline PUT & /ring/rainbow/ & $\begin{array}{l}\text { Starts a color rainbow } \\
\text { https://vimeo.com/122884367 }\end{array}$ \\
\hline PUT & /ring/rainbow/circle/ & Starts a color rainbow cycle \\
\hline PUT & /ring/color/ & $\begin{array}{l}\text { Changes the color of the LED strip. The } \\
\text { color values (red, green, blue) are } \\
\text { provided as a JSON object: }\{\text { "r": x,"g": } \\
\text { x,"b": x } \\
\text { https://vimeo.com/122884368 }\end{array}$ \\
\hline \hline & & $\begin{array}{l}\text { Changes the color of a LED pixel. The } \\
\text { pixel values (number, red, green, blue) } \\
\text { are provided as a JSON object: }\{\text { "n": } \\
\text { x,"r": x,"g": x, "b":x }\}\end{array}$ \\
\hline PUT & /ring/pixel/ & $\begin{array}{l}\text { Changes the color of a LED pixel range. } \\
\text { The pixel values (number1, number2, } \\
\text { red, green, blue) are provided as a JSON } \\
\text { object: }\{\text { "n1": x, "n2":x ,"r": x,"g": x, } \\
\text { "b":x }\}\end{array}$ \\
\hline PUT & /ring/pixel/range/ \\
\hline & &
\end{tabular}




\section{APPENDIX II}

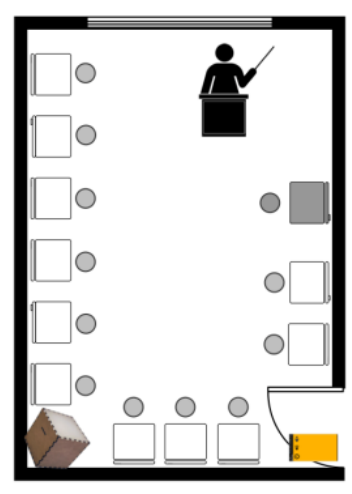

(a)

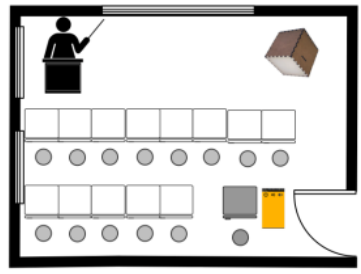

(c)

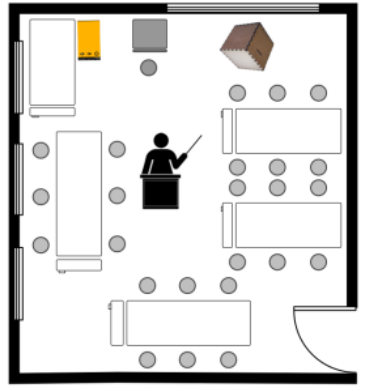

(b)

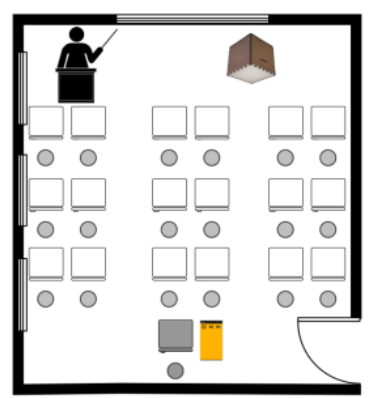

(d)
Fig. 6. Classrooms' distribution where the experiment took place. (a) Illustrates individual-work classroom, (b) illustrates work-in-group classroom, whereas (c) and (d) illustrate alternative lecture-session classrooms.

\section{ACKNOWLEDGMENT}

The authors would like to thank I.E., S. Emilio Jimeno de Calatayud (Zaragoza) and Dra. Covadonga Rodrigo for their support in this research. Moreover, the authors would like to thank the associate editor and the reviewers for their constructive comments and useful insights, which significantly improved the paper.

\section{REFERENCES}

[1] B. Berglund, T. Lindvall, and D. H. Schwela, "New Who Guidelines for Community Noise," Noise Vibration Worldwide, vol. 31, no. 4, pp. 24-29, Apr. 2000, doi: 10.1260/0957456001497535.

[2] A. Calvo-Manzano and J. Garrido, "Programa de concienciación sobre el ruido," Sociedad Española de Acústica, Madrid, Spain, Nov. 3, 2020. [Online]. Available: http://www.seaacustica.es/fileadmin/Otras\%20publicaciones/Unidad_didactica_sobre_el _ruido_para_ensenanza_secundaria.pdf

[3] M. F. Cheesman, M. B. Jennings, and L. Klinger, "Assessing communication accessibility in the university classroom: Towards a goal of universal hearing accessibility," Work, vol. 46, no. 2, pp. 139-150, 2013, doi: 10.3233/wor-131742.

[4] M. P. Jimenez-Tejada, J. A. Hodar, and F. Gonzalez-Garcia, "Noise, what noise? Raising awareness of auditory health among future primary-school teachers," Teaching and Teacher Education, vol. 28, no. 8, pp. 1083-1090, 2012, doi: 10.1016/j.tate.2012.06.002.

[5] T. Norlander, L. Moas, and T. Archer, "Noise and stress in primary and secondary school children: Noise reduction and increased concentration ability through a short but regular exercise and relaxation program," School Effectiveness and School Improvement, vol. 16, no. 1, pp. 91-99, 2005, doi:
10.1080/092434505000114173.

[6] D. Welch, R. Reddy, J. Hand, and I. M. Devine, "Educating teenagers about hearing health by training them to educate children," Int. J. of Audiology, vol. 55, no. 9, pp. 499-506, 2016, doi: 10.1080/14992027.2016.1178859.

[7] M. A. Crook and F. J. Langdon, "The effects of aircraft noise in schools around London Airport," J. of Sound and Vibration, vol. 34, no. 2, pp. 221-232, 1974, doi: 10.1016/S0022-460X(74)80306-8

[8] E. Johnson, "Let's Hear It for Learning.," American School \& University, vol. 73 , no. 11 , pp. 28-30, 2001.

[9] D. W. Downs and M. A. Crum, "Processing demands during auditory learning under degraded listening conditions," J. Speech Hear. Res., vol. 21, no. 4, pp. 702-714, 1978, doi: 10.1044/jshr.2104.702.

[10] A. L. Bronzaft and D. P. McCarthy, "The effect of elevated train noise on reading ability," Environment and Behavior, vol. 7, no. 4, pp. 517-528, 1975, doi: 10.1177/001391657500700406.

[11] G. W. Evans and L. Maxwell, "Chronic noise exposure and reading deficits: The mediating effects of language acquisition," Environment and Behavior, vol. 29, no. 5, pp. 638-656, 1997, doi: 10.1177/0013916597295003.

[12] B. L. Kyzar, "Noise Pollution and Schools: How Much Is Too Much?.," CEFP J.., vol. 15, no. 2, pp. 10-11, 1977.

[13] S. Reis and N. Correia, "The perception of sound and its influence in the classroom," In Lecture Notes in Computer Science, pp. 609-626, Sep. 2011, doi: 10.1007/978-3-642-23774-4_48.

[14] M. Bistrup, "Children and noise-prevention of adverse effects," Noise and Health, vol. 5, no. 19, pp. 59-64, 2003.

[15] N. S. Chatzakis, A. D. Karatzanis, M. E. Helidoni, S. G. Velegrakis, P. Christodoulou, and G. A. Velegrakis, "Excessive noise levels are noted in kindergarten classrooms in the island of Crete," Eur. Arch. Oto-RhinoLaryngology, vol. 271, pp. 483-487, 2014, doi: 10.1007/s00405-0132442-z.

[16] K. T. Mealings, K. Demuth, J. M. Buchholz, and H. Dillon, "The effect of different open plan and enclosed classroom acoustic conditions on speech perception in Kindergarten children," J. Acoust. Soc. Am., vol. 138, no. 4, pp. 2458-2469, 2015, doi: 10.1121/1.4931903.

[17] D. Skarlatos and M. Manatakis, "Effects of classroom noise on students and teachers in Greece," Perceptual and Motor Skills, vol. 96, no. 2, pp. 539-544, 2003, doi: 10.2466/PMS.96.2.539-544.

[18] E. Ibem, O. Alagbe, and A. Owoseni, "A study of students' preception of the learning environment: case study of department of architecture, Covenant University, OTA Ogun State," in Inted2017: 11th Int. Technology, Education and Development Conf., L. G. Chova, A. L. Martinez, and I. C. Torres, Eds. 2017, pp. 6275-6286, doi: 10.21125/inted.2017.1455.

[19] L. M. Ronsse and L. M. Wang, "Relationships between unoccupied classroom acoustical conditions and elementary student achievement measured in eastern Nebraska," J. Acoust. Soc. Am., vol. 133, no. 3, pp. 1480-1495, 2013, doi: 10.1121/1.4789356.

[20] J. Radosz, "Influence of classrooms acoustics on the teachers' voice sound pressure level," Medycyna pracy., vol. 63, no. 4, pp. 409-417, 2012.

[21] L. Ramma, "Rethinking our classrooms: assessment of background noise levels and reverberation in schools," Education as Change., vol. 11, no. 2, pp. 115-130, 2007, doi: 10.1080/16823200709487169.

[22] P. H. T. Zannin and C. R. Marcon, "Objective and subjective evaluation of the acoustic comfort in classrooms," Applied Ergonomics., vol. 38, no. 5, pp. 675-680, 2007, doi: 10.1016/j.apergo.2006.10.001.

[23] K. J. Brannstrom, E. Johansson, D. Vigertsson, D. J. Morris, B. Sahlen, and V. Lyberg-Ahlander, "How Children Perceive the Acoustic Environment of Their School," Noise Health, vol. 19, no. 87, pp. 84-94, 2017, doi: 10.4103/nah.NAH_33_16.

[24] L. Maffei, G. Iannace, M. Masullo, and P. Nataletti, "Noise exposure in school gymnasia and swimming pools," Noise Control Eng. J., vol. 57, no. 6, pp. 603-612, 2009, doi: 10.3397/1.3155385.

[25] A. Hurtig, P. Sorqvist, R. Ljung, S. Hygge, and J. Ronnberg, "Student's Second-Language Grade May Depend on Classroom Listening Position," PLoS One, vol. 11, no. 6, 2016, doi: 10.1371/journal.pone.0156533.

[26] M. Matheson et al., "The effects of road traffic and aircraft noise exposure on children's episodic memory: The RANCH Project," Noise Health, vol. 12, no. 49, pp. 244-254, 2010. doi: 10.4103/1463-1741.70503.

[27] S. Hygge, E. Boman, and I. Enmarker, "The effects of road traffic noise and meaningful irrelevant speech on different memory systems," Scandinavian J. Psychol., vol. 44, no. 1, pp. 13-21, 2003, doi: 10.1111/1467-9450.00316.

[28] C. Hollander and V. M. de Andrade, "The Effects of Aircraft Noise on the 
Auditory Language Processing Abilities of English First Language Primary School Learners in Durban, South Africa," Urban Educ., vol. 49, no. 7, pp. 783-805, 2014, doi: 10.1177/0042085913488604.

[29] S. A. Stansfeld et al., "Aircraft and road traffic noise and children"s cognition and health: a cross-national study," Lancet, vol. 365, no. 9475, pp. 1942-1949, 2005, 10.1016/S0140-6736(05)66660-3.

[30] H. Noh and Y.-G. Park, "How close should a student with unilateral hearing loss stay to a teacher in a noisy classroom?," Int. J. Audiology., vol. 51, no. 6, pp. 426-432, 2012, doi: 10.3109/14992027.2012.654855.

[31] S. P. Meuer and W. Hiller, "The impact of hyperacusis and hearing loss on tinnitus perception in German teachers," Noise Health, vol. 17, no. 77, pp. 182-190, 2015, doi: 10.4103/1463-1741.160682.

[32] M. Klatte, K. Bergström, and T. Lachmann, "Does noise affect learning? A short review on noise effects on cognitive performance in children.," Frontiers Psychol., vol. 4, no. August, p. 578, 2013, doi: 10.3389/fpsyg.2013.00578.

[33] M. Klatte, T. Lachmann, and M. Meis, "Effects of noise and reverberation on speech perception and listening comprehension of children and adults in a classroom-like setting," Noise Health, vol. 12, no. 49, pp. 270-282, 2010, doi: 10.4103/1463-1741.70506.

[34] K. T. Mealings, K. Demuth, J. Buchholz, and H. Dillon, "The Development of the Mealings, Demuth, Dillon, and Buchholz Classroom Speech Perception Test," J. Speech Language Hearing Res., vol. 58, no. 4, pp. 1350-1362, 2015, doi: 10.1044/2015_JSLHR-H-14-0332.

[35] W. Lin, H. Lin, and K.-H. Huang, "Improving Speech Intelligibility in Classrooms by Decreasing Sound Energy of Low Frequency," in Universal Access in Human-Computer Interaction: Access to Interaction, Pt II, vol. 9176, M. Antona and C. Stephanidis, Eds. 2015, pp. 464-473, doi: 10.1007/978-3-319-20681-3_44.

[36] J. Peng, N. Yan, and D. Wang, "Chinese speech intelligibility and its relationship with the speech transmission index for children in elementary school classrooms," J. Acoust. Soc. Am., vol. 137, no. 1, pp. 85-93, 2015, doi: 10.1121/1.4904519.

[37] M. Fahlstrom, "Mathematics Teachers' Conceptions of the Classroom Environment," In Teaching and Learning in Maths Classrooms, Springer, pp. 141-151, 2017, doi: 10.1007/978-3-319-49232-2_14.

[38] G. P. Korn, A. A. de Lima Pontes, D. Abranches, and P. A. de Lima Pontes, "Hoarseness and Risk Factors in University Teachers," J. Voice, vol. 29, no. 4, 2015, doi: 10.1016/j.jvoice.2014.09.008.

[39] L. C. C. Cutiva and A. Burdorf, "Effects of noise and acoustics in schools on vocal health in teachers," Noise Health, vol. 17, no. 74, pp. 17-22, 2015, doi: 10.4103/1463-1741.149569.

[40] U. Devadas, R. Bellur, and S. Maruthy, "Prevalence and Risk Factors of Voice Problems Among Primary School Teachers in India," J. Voice, vol. 31, no. 1, 2017, doi: 10.1016/j.jvoice.2016.03.006.

[41] J. Kristiansen, S. P. Lund, R. Persson, H. Shibuya, P. M. Nielsen, and M. Scholz, "A study of classroom acoustics and school teachers' noise exposure, voice load and speaking time during teaching, and the effects on vocal and mental fatigue development," Int. Archives Occuppational Environ. Health, pp. 1-10, 2014, doi: 10.1007/s00420-014-0927-8.

[42] L. C. C. Cutiva, I. Vogel, and A. Burdorf, "Voice disorders in teachers and their associations with work-related factors: A systematic review," $J$. Commun. Disord., vol. 46, no. 2, pp. 143-155, 2013, doi: 10.1016/j.jcomdis.2013.01.001.

[43] M. C. Franca, "A comparison of vocal demands with vocal performance among classroom student teachers," J. Commun. Disorders, vol. 46, no. 1, pp. 111-123, 2013, doi: 10.1016/j.jcomdis.2013.01.001.

[44] S. Simberg, E. Sala, K. Vehmas, and A. Laine, "Changes in the prevalence of vocal symptoms among teachers during a twelve-year period," J. Voice, vol. 19, no. 1, pp. 95-102, 2005, doi: 10.1016/j.jvoice.2004.02.009.

[45] T. W. Teasdale and M. H. Sorensen, "Hearing loss in relation to educational attainment and cognitive abilities: A population study," Int. $J$. Audiology, vol. 46, no. 4, pp. 172-175, 2007, doi: $10.1080 / 14992020601089484$.

[46] J. Kristiansen et al., "The effects of acoustical refurbishment of classrooms on teachers' perceived noise exposure and noise-related health symptoms," Int. Archives Occupational Environ. Health, vol. 89, no. 2, pp. 341-350, 2016, doi: 10.1007/s00420-015-1077-3.

[47] S. Ubillos, J. Centeno, J. Ibanez, and I. Iraurgi, "Protective and Risk Factors Associated With Voice Strain Among Teachers in Castile and Leon, Spain: Recommendations for Voice Training," J. Voice, vol. 29, no. 2, 2015, doi: 10.1016/j.jvoice.2014.08.005.

[48] P. Lercher, G. W. Evans, M. Meis, and W. W. Kofler, "Ambient neighbourhood noise and children's mental health," Occupational Environ. Med., vol. 59, no. 6, pp. 380-386, 2002, doi: 10.1136/oem.59.6.380.

[49] R. Walinder, K. Gunnarsson, R. Runeson, and G. Smedje, "Physiological and psychological stress reactions in relation to classroom noise," Scandinavian J. Work Environ. Health, vol. 33, no. 4, pp. 260-266, 2007, 10.5271/sjweh.1141.

[50] H. M. Mustafa, S. Mahmoud, A. Al-Hamadi, Z. M. Abdulhamid, and A. M. Al-Bassiouni, "On quantified evaluation of noisy data impact on children's mental development using artificial neural networks," In Proc. ICERI2013, IATED, pp. 4069-4077, 2017.

[51] C. Guardino and S. D. Antia, "Modifying the Classroom Environment to Increase Engagement and Decrease Disruption with Students Who Are Deaf or Hard of Hearing," J. Deaf Studies Deaf Educ., vol. 17, no. 4, pp. 518-533, 2012, doi: 10.1093/deafed/ens026.

[52] R. Persson, J. Kristiansen, S. P. Lund, H. Shibuya, and P. M. Nielsen, "Classroom acoustics and hearing ability as determinants for perceived social climate and intentions to stay at work," Noise Health, vol. 15, no. 67, pp. 446-453, 2013, 10.4103/1463-1741.121254.

[53] P. Lundquist, K. Holmberg, L. Burstrom, and U. Landstrom, "Sound levels in classrooms and effects on self-reported mood among school children," Perceptual Motor Skills, vol. 96, no. 3, pp. 1289-1299, 2003, doi: 10.2466/PMS.96.3.1289-1299.

[54] ASHA, "Classroom Acoustics,", Nov. 3, 2020. [Online]. Available: http https://www.asha.org/practice-portal/professional-issues/classroomacoustics/

[55] B. Tabuenca, M. Kalz, H. Drachsler, and M. Specht, "Time will tell: The role of mobile learning analytics in self-regulated learning," Comput. Educ., vol. 89, pp. 53-74, Nov. 2015, doi: 10.1016/j.compedu.2015.08.004.

[56] B. Tabuenca, M. Kalz, S. Ternier, and M. Specht, "Stop and think: Exploring mobile notifications to foster reflective practice on metalearning," IEEE Trans. Learn. Technol., vol. 8, no. 1, 2015, doi: 10.1109/TLT.2014.2383611.

[57] B. Tabuenca, D. Börner, M. Kalz, and M. Specht, "User-Modelled Ambient Feedback for Self-regulated Learning," in Lecture Notes in Computer Science, vol. 9307, pp. 535-539, 2015, doi: 10.1007/978-3319-24258-3_54.

[58] N. Gligori, T. Dim, S. Krčo, S. Member, and V. Dim, "Internet of Things enabled LED lamp controlled by satisfaction of students in a classroom," IPSI Bgd Internet Res. Soc., pp. 1-4, 2014.

[59] P. B. Lyk and M. Lyk, "Nao as an Authority in the Classroom," in Proc. Tenth Annu. ACM/IEEE Int. Conf. on Human-Robot Interaction Extended Abstracts - HRI'15 Extended Abstracts, pp. 77-78, 2015, doi: 10.1145/2701973.2702014.

[60] J. van Tonder, N. Woite, S. Strydom, F. Mahomed, and D. W. Swanepoel, "Effect of visual feedback on classroom noise levels," South African J. Childhood Educ., vol. 5, no. 3, 2015, doi: 10.4102/sajce.v5i3.265.

[61] S. G. R. Prakash, R. Rangasayee, and P. Jeethendra, "Low cost assistive noise level indicator for facilitating the learning environment of school going children with hearing disability in inclusive educational setup," Indian J. Sci. Technol., 2011, doi: 10.17485/ijst/2011/v4i11/30277.

[62] S. Reis and N. Correia, "The perception of sound and Its influence in the classroom," in Lecture Notes in Computer Science, pp. 609-626, 2011, doi: 10.1007/978-3-642-23774-4_48.

[63] C. Wisneski et al., "Ambient Displays: Turning Architectural Space into an Interface between People and Digital Information," in Lecture Notes in Computer Science, pp. 22-32, 1998, doi: 10.1007/3-540-69706-3_4.

[64] D. Börner, M. Kalz, and M. Specht, "Lead me gently: Facilitating knowledge gain through attention-aware ambient learning displays," Comput. Educ., vol. 78, pp. 10-19, Sep. 2014, doi: 10.1016/j.compedu.2014.04.017.

[65] D. Börner, M. Kalz, and M. Specht, "Beyond the channel: A literature review on ambient displays for learning," Comput. Educ., vol. 60, no. 1, pp. 426-435, 2013, doi: 10.1016/j.compedu.2012.06.010.

[66] D. Börner, J. Storm, M. Kalz, and M. Specht, "Energy awareness displays: motivating conservation at the workplace through feedback," Int. J. Mobile Learning Organisation, vol. 6, no. 3/4, 2012, 10.1504/IJMLO.2012.050048.

[67] D. Börner, M. Kalz, and M. Specht, "It doesn't matter, but: examining the impact of ambient learning displays on energy consumption and conservation at the workplace," Environ. Educ. Res., vol. 21, no. 6, pp. 899-915, 2015, doi: 10.1080/13504622.2014.921804.

[68] K. Kappel and T. Grechenig, 'Show-Me': Water Consumption At a Glance To Promote Water Conservation in the Shower," In Proc. 4th Int. Conf. Persuas. Technol., pp. 1-6, 2009, doi: 10.1145/1541948.1541984.

[69] J. Ham and C. Midden, "Ambient persuasive technology needs little 
cognitive effort: The differential effects of cognitive load on lighting feedback versus factual feedback," in Lecture Notes in Computer Science, vol. 6137, pp. 132-142, 2010, doi: 10.1007/978-3-642-13226-1_14.

[70] S. Lu, J. Ham, and C. J. H. Midden, "Using Ambient Lighting in Persuasive Communication: The Role of Pre-existing Color Associations," in Lecture Notes in Computer Science, vol. 8462, pp. 167178, 2014, doi: 10.1007/978-3-319-07127-5_15.

[71] T. Nakajima and V. Lehdonvirta, "Designing motivation using persuasive ambient mirrors," Pers. Ubiquitous Comput., vol. 17, pp. 107-126, 2013, doi: 10.1007/s00779-011-0469-y.

[72] J. Brownell, Listening: Attitudes, Principles, and Skills. Oxon, UK: Routledge, 2015.

[73] H. Bourdeaud'hui, K. Aesaert, H. Van Keer, and J. van Braak, "Identifying student and classroom characteristics related to primary school students' listening skills: A systematic review," Educational Res. Rev., vol. 25, pp. 86-99, 2018, doi: 10.1016/j.edurev.2018.09.005.

[74] P. Woolner and E. Hall, "Noise in Schools: A Holistic Approach to the Issue," Int. J. Environ. Res. Public Health, vol. 7, no. 8, pp. 3255-3269, 2010, doi: 10.3390/ijerph7083255.

[75] P. Woźniak and B. Koczorowicz, "SubRosa: Supporting a Proper Learning Atmosphere through Subtle Cues with Immediate Feedback," In Lecture Notes in Computer Science, vol. 8462, pp. 279-290, 2014, doi: 10.1007/978-3-319-07127-5_25.

[76] T. Sitzman, K. Ely, K. G. Brown, and K. N. Bauer, "Self-Assessment of Knowledge: A Cognitive Learning or Affective Measure?," Acad. Manag. Learn. Educ., vol. 9, no. 2, pp. 169-191, Jun. 2010, doi: 10.5465/amle.9.2.zqr169.

[77] D. Dunning, C. Heath, and J. M. Suls, "Flawed self-assessment implications for health, education, and the workplace," Psychological Sci. Public Interest, vol. 5, no. 3, pp. 69-106, 2004, doi: 10.1111/j.15291006.2004.00018.x.

[78] M. E. Sullivan, M. A. Hitchcock, and G. L. Dunnington, "Peer and self assessment during problem-based tutorials," Am. J. Surgery, vol. 177, no. 3, pp. 266-269, 1999, doi: 10.1016/s0002-9610(99)00006-9.

[79] E. Hornecker and J. Buur, "Getting a grip on tangible interaction," in Proc. SIGCHI Conf. on Human Factors in computing systems, pp. 437-446, 2006, doi: 10.1145/1124772.1124838.

[80] D. Börner, B. Tabuenca, J. Storm, S. Happe, and M. Specht, "Tangible Interactive Ambient Display Prototypes to Support Learning Scenarios," in Proc. 9th Int. Conf. on Tangible, Embedded, and Embodied Interaction, pp. 721-726, 2015, doi:10.1145/2677199.2687908.

[81] J. C. Nunnally and I. Bernstein, Psychometric Theory, vol. 226. New York, New York, USA: McGraw-Hill, 1967.

[82] J. D. Evans, Straightforward statistics for the behavioural science. Pacific Grove, California, USA: Brooks/Cole Publishing Company, 1996.

[83] D. E. Clayson, "Student Evaluations of Teaching: Are They Related to What Students Learn?," J. Marketing Educ., vol. 31, no. 1, pp. 16-30, Apr. 2009, doi: 10.1177/0273475308324086.

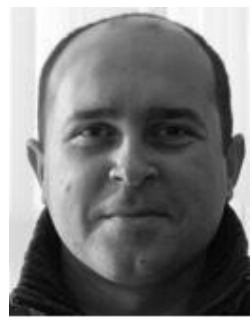

Bernardo Tabuenca is Assistant Professor at the Information Systems Department at the Technical University of Madrid (Spain). Bernardo conducted his research at the Research Centre for Learning, Teaching and Technology of the Open University of The Netherlands where he obtained his $\mathrm{PhD}$. His current areas of research include technology-enhanced learning, IoT, ubiquitous technology, open education, and lifelong learning.

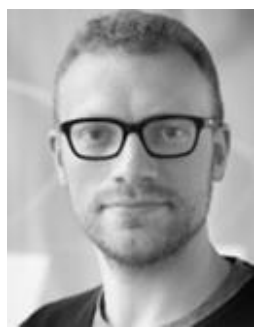

Dirk Börner is project mamager and senior developer at the Intelligent Enterprise Technology unit of SAP SE. Previously he has worked as assistant professor at the Welten Institute at the Open University of the Netherlands where he obtained his PhD. He focuses on the utilization of ambient information presentation in combination with mobile technology to support learners in authentic situations.

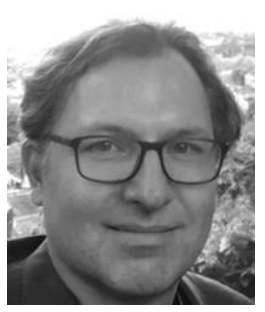

Marco Kalz is full professor of technology-enhanced learning at the Heidelberg University of Education (Germany) and UNESCO chair of open education at the Open University of the Netherlands. His research interest lies on the use of open education, pervasive technologies and formative assessment to support self-directed lifelong learning. 